\title{
THERMAL CHARACTERISTICS OF HIGH TEMPERATURE NATURALLY CIRCULATING HELIUM COOLING LOOP
}

\author{
DZIANIK František ${ }^{1}$, GUŽELA Štefan ${ }^{1}$, PUŠKÁŠOVÁ Eva ${ }^{1}$ \\ ${ }^{1}$ Slovak University of Technology in Bratislava, Faculty of Mechanical Engineering, Institute of Process \\ Engineering, Nám. slobody 17, 81231 Bratislava, Slovakia, \\ e-mail:frantisek.dzianik@stuba.sk,stefan.guzela@stuba.sk,eva.puskasova@stuba.sk
}

\begin{abstract}
The paper deals with the process properties in terms of the heat transfer, i.e. the thermal performance of the thermal-process units within a helium loop intended for the testing of the decay heat removal (DHR) from the model of the gas-cooled fast reactor (GFR). The system is characterised by a natural circulation of helium, as a coolant, and assume the steady operating conditions of the circulation. The helium loop consists of four main components: the model of the gas-cooled fast reactor, the model of the heat exchanger for the decay heat removal, hot piping branch and cold piping branch. Using the thermal calculations, the thermal performance of the heat exchanger model and the thermal performance of the gas-cooled fast reactor model are determined. The calculations have been done for several defined operating conditions which correspond to the different helium flow rates within the system.
\end{abstract}

KEYWORDS: helium cooling loop, thermal characteristics, heat transfer calculation, heat exchanger, decay heat removal (DHR)

\section{Introduction}

The incentive for the development of new technologies in the field of the nuclear energy is to achieve a better efficiency, a highest safety and reliability as well as to minimise the production of the radioactive waste. Several new types of the nuclear power reactors are currently the subject of the research in this area. The perspective types of the nuclear reactors are also the gas-cooled fast reactors (GFR) which rank among the so-called Generation IV reactors. A suitable heat transfer medium of the primary circuit system and the decay heat removal system in such gas-cooled fast reactors appears helium. For this reason, the research of the helium cooling loop systems is very topical. The research activities in the given area from several aspects are documented in the various publications, as for example $[1,2,3,4,5$, $6,7,8]$.

The cooling loop systems can be divided from a process point of view into the systems with forced or natural circulation of the cooling fluid. Helium cooling loop, which the thermal process properties are presented in this paper, can be defined as a model of the passive safety feature serving to an emergency heat removal from the fast reactor working space (active zone of the gas-cooled fast reactor). From a process point of view, the operation of such helium cooling loop is based on a combination of the thermal and the hydrodynamic processes that are interdependent. A very significant influence on the qualitative and quantitative side of the thermo-hydrodynamic processes has the geometric configuration of the system. The hydrodynamic process properties of such a helium cooling loop are presented in the paper [7]. 


\section{The description of the operation and the configuration of high temperature helium cooling loop}

The high temperature helium cooling loop (Fig. 1) is an experimental device that allows testing of the decay heat removal (DHR) from the model of the gas-cooled fast reactor (GFR). The cooling loop consists of four main components: the model of the gas-cooled fast reactor (1), the model of the heat exchanger for the decay heat removal (2), hot piping branch (3) and cold piping branch (4). In terms of the thermal processes, the GFR model and the DHR heat exchanger model are important. The GFR model is used to simulate a source of the decay heat generated by an electric heating through the heating elements (rods). The model of the DHR heat exchanger is used for the heat removal which is generated in the reactor model. This is a shell and tube heat exchanger with U-tubes (Fig. 2). The primary heat transfer fluid is helium. The secondary cooling fluid in the DHR heat exchanger model is water. The cooling water flows in the tube side and helium in the shell side of the heat exchanger model.

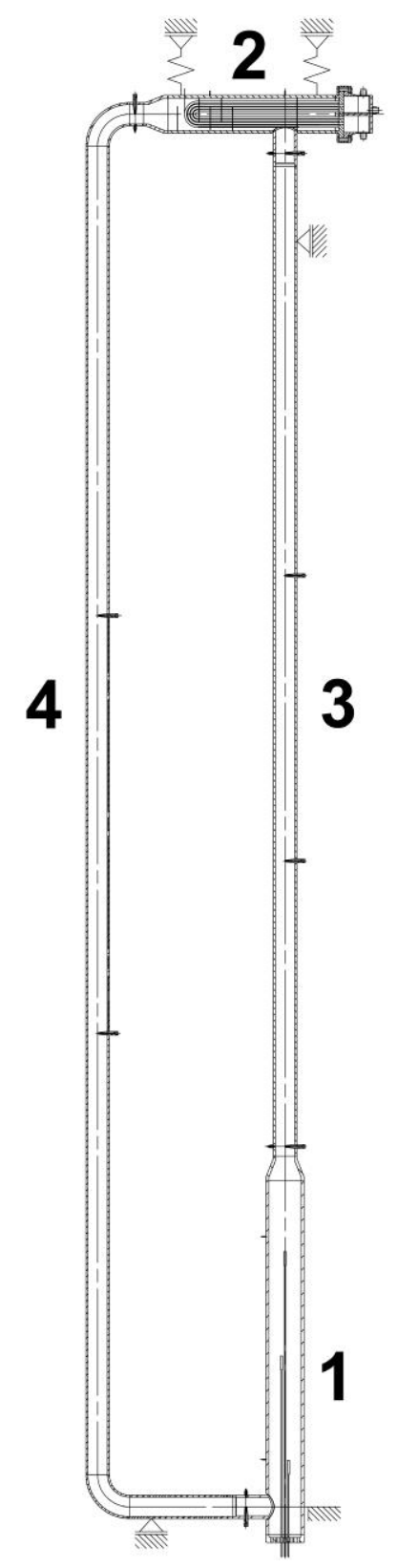

Fig. 1 High temperature helium cooling loop [5] (1 - GFR model, 2 - DHR heat exchanger model, 3 - hot piping branch, 4 - cold piping branch) 
The helium cooling loop must ensure a passive heat removal from the reactor model, i.e., it must be achieved a sufficiently intensive natural circulation (circulation caused by the effect of gravity) of helium in the cooling system due to a helium density difference in the cold and hot piping branch. Within such helium circulation the appropriate thermo-hydrodynamic conditions have to be achieved in the reactor model in order to ensure the desired heat flow rate removal from the surface of the heating elements (rods) to the heat transfer fluid (helium). In order to ensure the steady transfer of this heat flow rate from helium to the cooling water, the appropriate thermo-hydrodynamic conditions have to be achieved simultaneously also in the heat exchanger model.

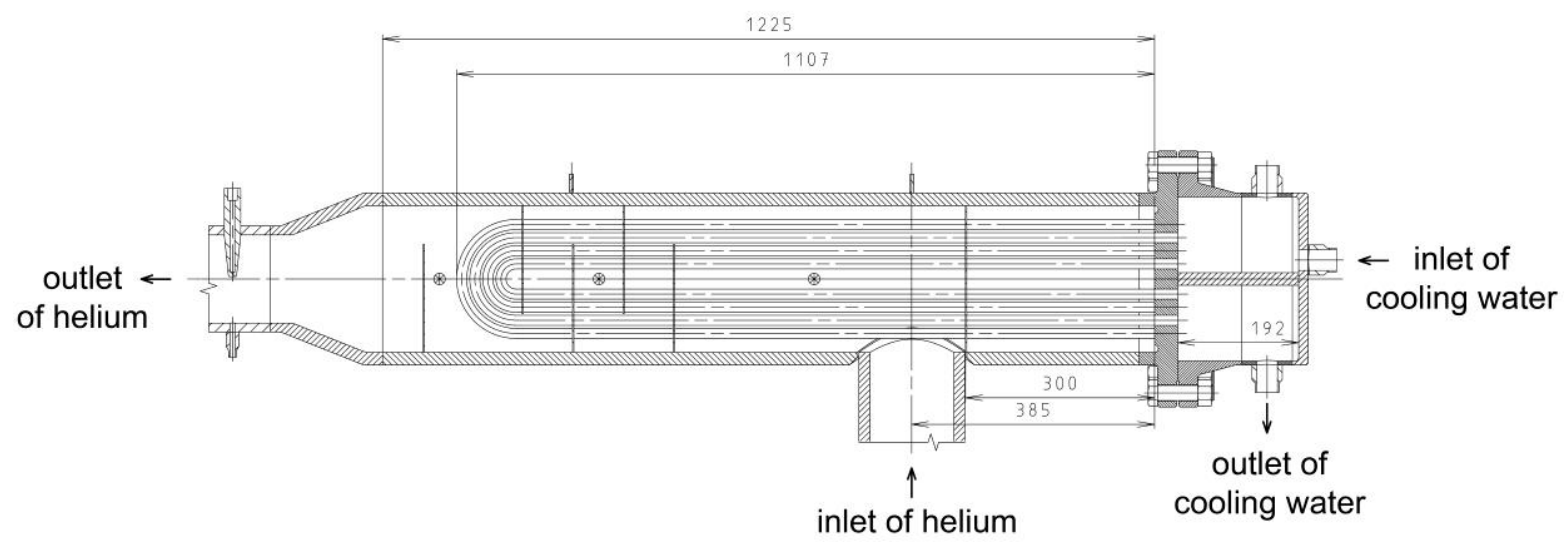

Fig. 2 The model of the heat exchanger for the decay heat removal (DHR) [5]

The helium section of the cylindrical shell $(\varnothing 273 \times 20 \mathrm{~mm})$ of the DHR heat exchanger model is made of low alloy heat resistant steel. The cooling water section of the shell as well as the tube bundle and the tube sheet are made of stainless steel. The tube bundle consists of twenty U-tubes $\varnothing 16 \times 1.5 \mathrm{~mm}$ with a length of $2.2 \mathrm{~m}$, which are fixed in the tube sheet. The heat exchanger shell side internals consists of some segmental baffles (baffle spacing $80 \mathrm{~mm}$ ) to direct the flow of helium and to support the tubes. The GFR model is a cylindrical pressure vessel $(\varnothing 273 \times 20 \mathrm{~mm})$ with a flat bottom and is made of low alloy heat resistant steel. The reactor model internals (Fig. 3) consists of the longitudinal heating rods $(8.5 \mathrm{~mm}$ in diameter and $2.5 \mathrm{~m}$ long) and the segmental baffles (baffle spacing $500 \mathrm{~mm}$ ) to direct the flow of helium and to support the heating rods.

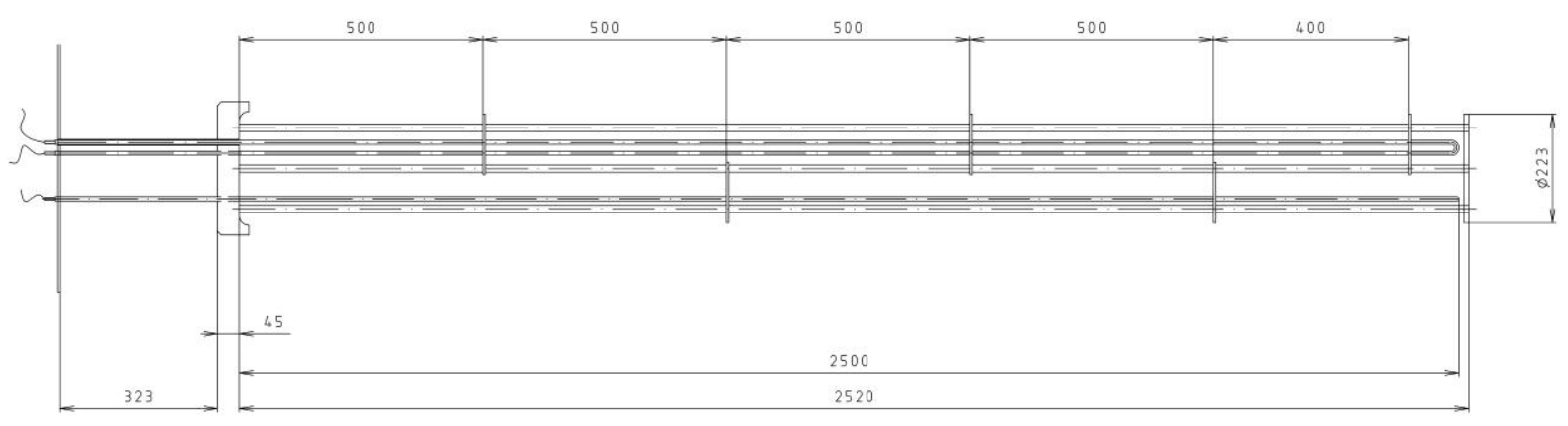

Fig. 3 The internals of the gas-cooled fast reactor (GFR) model [5]

\section{Methodology and the conditions of thermal calculations}

Thermal process calculations of the heat exchanger model for decay heat removal (DHR) and of the model of the gas-cooled fast reactor (GFR) have been performed for the defined operating conditions, as listed in Tab. 1. The methodology of process calculations of the heat 
exchangers may be found in the various specialised publications such as the VDI-Wärmeatlas [9].

Tab. 1 Defined operating conditions for the thermal process calculations of the DHR heat exchanger model and of the gas-cooled fast reactor model.

\begin{tabular}{|l|c|c|}
\hline \multicolumn{1}{|c|}{ Parameter } & Symbol & Value \\
\hline Operating pressure of helium & $p_{H e}(\mathrm{MPa})$ & 7 \\
Heat exchange area of the heat exchanger model & $A\left(\mathrm{~m}^{2}\right)$ & 1.553 \\
Mean value of the thermal conductivity coefficient of the heat & $\bar{\lambda}$ & 15 \\
exchange wall & $\left(\mathrm{W} . \mathrm{m}^{-1} \cdot \mathrm{K}^{-1}\right)$ & \\
Temperature of helium at the inlet of the heat exchanger model & $T_{H e E I}\left({ }^{\circ} \mathrm{C}\right)$ & 520 \\
Temperature of cooling water at the inlet of the heat exchanger model & $T_{W E I}\left({ }^{\circ} \mathrm{C}\right)$ & 15 \\
Temperature of cooling water at the outlet of the heat exchanger model & $T_{W E O}\left({ }^{\circ} \mathrm{C}\right)$ & 45 \\
Total heating surface of the heating rods in the reactor model & $A_{R}\left(\mathrm{~m}^{2}\right)$ & 4.23 \\
Temperature of helium at the inlet of the reactor model & $T_{H e R I}\left({ }^{\circ} \mathrm{C}\right)$ & 150 \\
\hline
\end{tabular}

For the thermal calculation of the DHR heat exchanger model, the balance equations of the enthalpy

$$
\begin{gathered}
Q=m_{H e E}\left(h_{H e E I}-h_{H e E O}\right)=m_{H e E} \bar{c}_{p H e E}\left(T_{H e E I}-T_{H e E O}\right), \\
Q=m_{W E}\left(h_{W E O}-h_{W E I}\right)=m_{W E} \bar{c}_{p W E}\left(T_{W E O}-T_{W E I}\right),
\end{gathered}
$$

as well as the kinetic equation for the heat flow $Q$ between helium and cooling water through the heat exchange wall of the heat exchanger

$$
Q=A \bar{k} \varepsilon_{\Delta \bar{T}} \Delta \bar{T}_{\mathrm{ln}}
$$

are used. The equations (1) and (2) contain the following variables related to the DHR heat exchanger model: the mass flow rates of helium $m_{H e E}$ and cooling water $m_{W E}$, specific enthalpies of helium at the inlet $h_{\mathrm{HeEI}}$ and at the outlet $h_{\mathrm{HeEO}}$, specific enthalpies of cooling water at the inlet $h_{W E I}$ and at the outlet $h_{W E O}$, mean values of the specific heat capacities of helium $\bar{c}_{p H e E}$ and of cooling water $\bar{c}_{p W E}$, the temperatures of helium at the inlet $T_{H e E I}$ and at the outlet $T_{H e E O}$ and the temperatures of cooling water at the inlet $T_{W E I}$ and at the outlet $T_{W E O}$. In the equation (3), $A$ is the heat exchange area of the heat exchanger, $\bar{k}$ is the mean value of the overall heat transfer coefficient which can be expressed by the equation

$$
\bar{k}=\frac{1}{\frac{1}{\bar{\alpha}_{H e E}}+\frac{b}{\bar{\lambda}}+\frac{1}{\bar{\alpha}_{W E}}}
$$


for the thin-walled tubes forming the heat exchange wall of the heat exchanger, $\Delta \bar{T}_{\mathrm{ln}}$ is the mean logarithmic temperature difference

$$
\Delta \bar{T}_{\mathrm{ln}}=\frac{\left(T_{H e E I}-T_{W E O}\right)-\left(T_{H e E O}-T_{W E I}\right)}{\ln \frac{T_{H e E I}-T_{W E O}}{T_{H e E O}-T_{W E I}}}
$$

and $\varepsilon_{\Delta \bar{T}}$ is the correction factor of the mean logarithmic temperature difference for a given heat exchanger design arrangement. In the equation (4), $\bar{\lambda}$ is the mean value of the thermal conductivity coefficient of the heat exchange wall and $b$ is the thickness of the heat exchange wall. Mean values of the heat transfer coefficients on the helium side $\bar{\alpha}_{H e E}$ and on the cooling water side $\bar{\alpha}_{W E}$ of the heat exchanger model can be determined using the similarity theory. The dimensionless heat transfer coefficient is most commonly expressed in the form of the Nusselt number $\mathrm{Nu}$, which is defined by the equation

$$
\mathrm{Nu}=\frac{\bar{\alpha} L}{\lambda_{f}},
$$

where $L$ is the characteristic dimension and $\lambda_{f}$ is the thermal conductivity of the fluid. Based on the similarity methods, the general functional relationship for the convective heat transfer can be written in the form: $\mathrm{f}\left(\mathrm{Nu}, \mathrm{Fo}, \mathrm{Re}, \mathrm{Gr}, \mathrm{Pr}, s_{1}, s_{2}, s_{3}, \ldots\right)=0$. The meaning of the variables in this relationship is as follows: Fo is the Fourier number, $\operatorname{Re}$ is the Reynolds number, Gr is the Grashof number, Pr is the Prandtl number and $s_{1}, s_{2}, s_{3}, \ldots$ are the other dimensionless parameters. On the basis of these mentioned relations, it is possible by the thermal calculation to determine the values of the mass flow rates of helium $m_{\mathrm{HeE}}$, the temperatures of helium at the outlet of the heat exchanger $T_{\text {HeEO }}$ and the mass flow rates of cooling water $m_{W E}$ for given values of the transferred heat flow rates $Q$ in the DHR heat exchanger model. The thermal calculation assumes the constant values of the following variables: the pressure of helium in the heat exchanger $p_{H e}$, the temperature of helium at the inlet of the heat exchanger $T_{H e E I}$, the temperature of cooling water at the inlet of the heat exchanger $T_{W E I}$ and the temperature of cooling water at the outlet of the heat exchanger $T_{W E O}$.

The thermal calculation methodology of the reactor model (GFR model) is similar to the thermal calculation methodology of the DHR heat exchanger model. However, through the GFR reactor model flows, unlike the heat exchanger, only one heat exchange fluid - helium, for which the balance equation of the enthalpy has the following form:

$$
Q=m_{H e R}\left(h_{H e R O}-h_{H e R I}\right)=m_{H e R} \bar{c}_{p H e R}\left(T_{H e R O}-T_{H e R I}\right) .
$$

The equation (7) contains the following variables related to the GFR reactor model: the mass flow rate of helium $m_{\mathrm{HeR}}$, specific enthalpies of helium at the inlet $h_{\mathrm{HeRI}}$ and at the outlet $h_{H e R O}$, mean value of the specific heat capacity of helium $\bar{c}_{p H e R}$ and the temperatures of helium at the inlet $T_{\text {HeRI }}$ and at the outlet $T_{\text {HeRO }}$. Heat transfer (heat flow) in the working space of the reactor model between the heating surface of the heating elements (rods) and helium can be expressed by the thermokinetic equation:

$$
Q=A_{R} q_{w}=A_{R} \bar{\alpha}_{H e R} \Delta \bar{T} .
$$


In the equation (8), $A_{R}$ is the total heating surface of the heating rods in the reactor model, $q_{w}$ is the heat flux on the surface of the heating rods, $\bar{\alpha}_{H e R}$ is the mean value of the heat transfer coefficient from the heating surface to the heated helium, $\Delta \bar{T}$ is the mean temperature difference between the temperature of the heating surface of the heating elements and the temperature of heated helium in the working space of the reactor model. The mass flow rates of helium $m_{\mathrm{HeR}}$ and the temperatures of helium at the outlet of the reactor model $T_{\text {HeRO }}$ are determined by the thermal calculation for given values of the transferred heat flow rates $Q$ in the reactor model. The thermal calculation assumes the constant values of the helium pressure in the reactor model $p_{H e}$ and of the helium temperatures at the inlet of reactor model $T_{H e R I}$.

\section{$4 \quad$ Results}

The results of the calculations are presented in the form of graphs. The Fig. 4 shows the dependence of the helium temperature at the outlet of the DHR heat exchanger $T_{H e E O}$ on the transferred heat flow rate $Q$ in this heat exchanger under the given conditions. The graph also contains the values of the corresponding helium mass flow $m_{\mathrm{HeE}}$ and the values of the pressure drop in the shell side of the DHR heat exchanger for helium $\Delta p_{d H e E}$. In the Fig. 5, the dependence of the helium temperature at the outlet of the gas-cooled fast reactor (GFR) model $T_{\text {HeRO }}$ on the transferred heat flow rate $Q$ in this reactor model is plotted under the given conditions. The graph also contains the values of the corresponding helium mass flow $m_{\mathrm{HeR}}$ and the values of the pressure drop in the reactor model for helium $\Delta p_{d H e R}$.

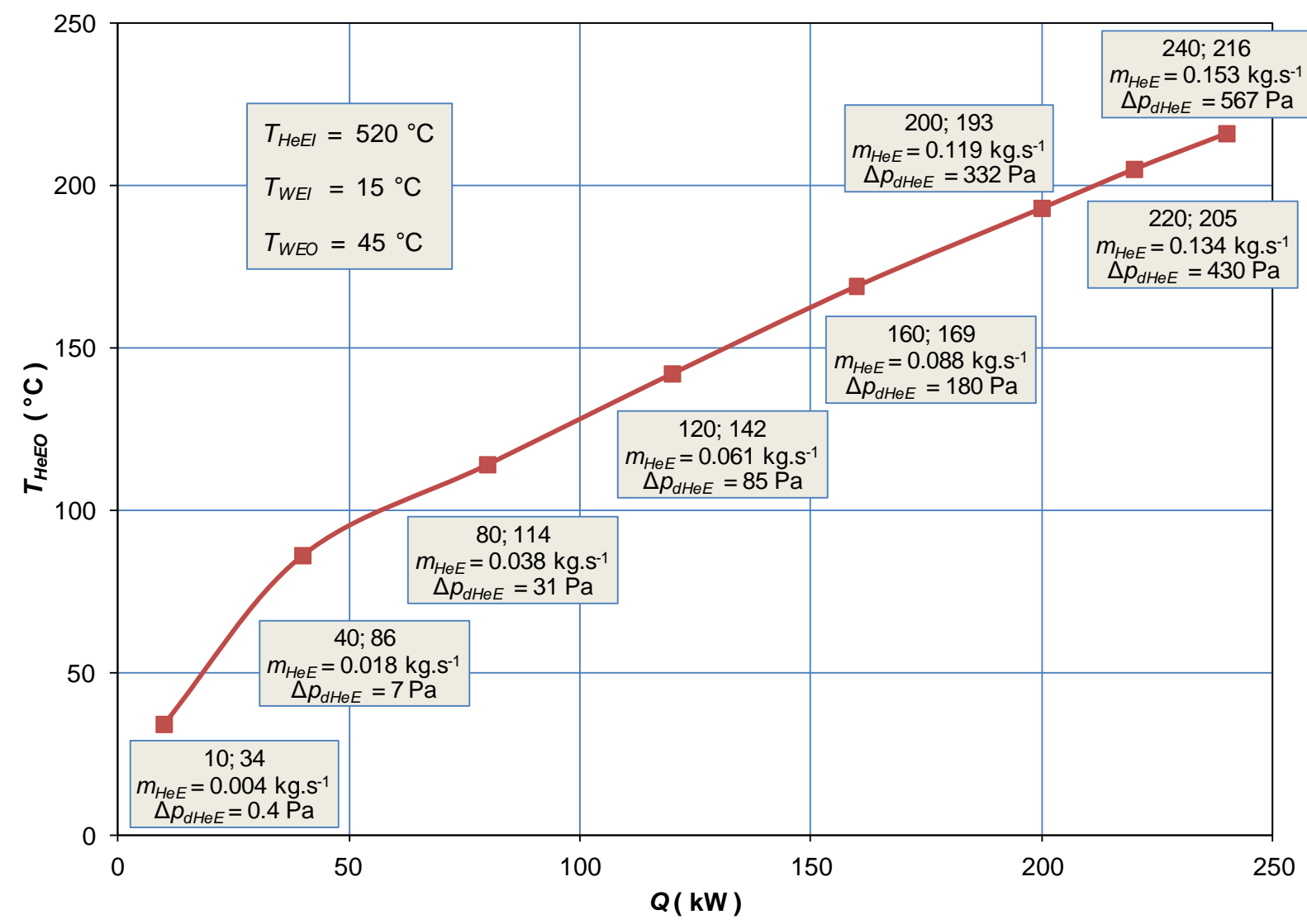

Fig. 4 The dependence of the helium temperature at the outlet of the DHR heat exchanger on the transferred heat flow rate. 


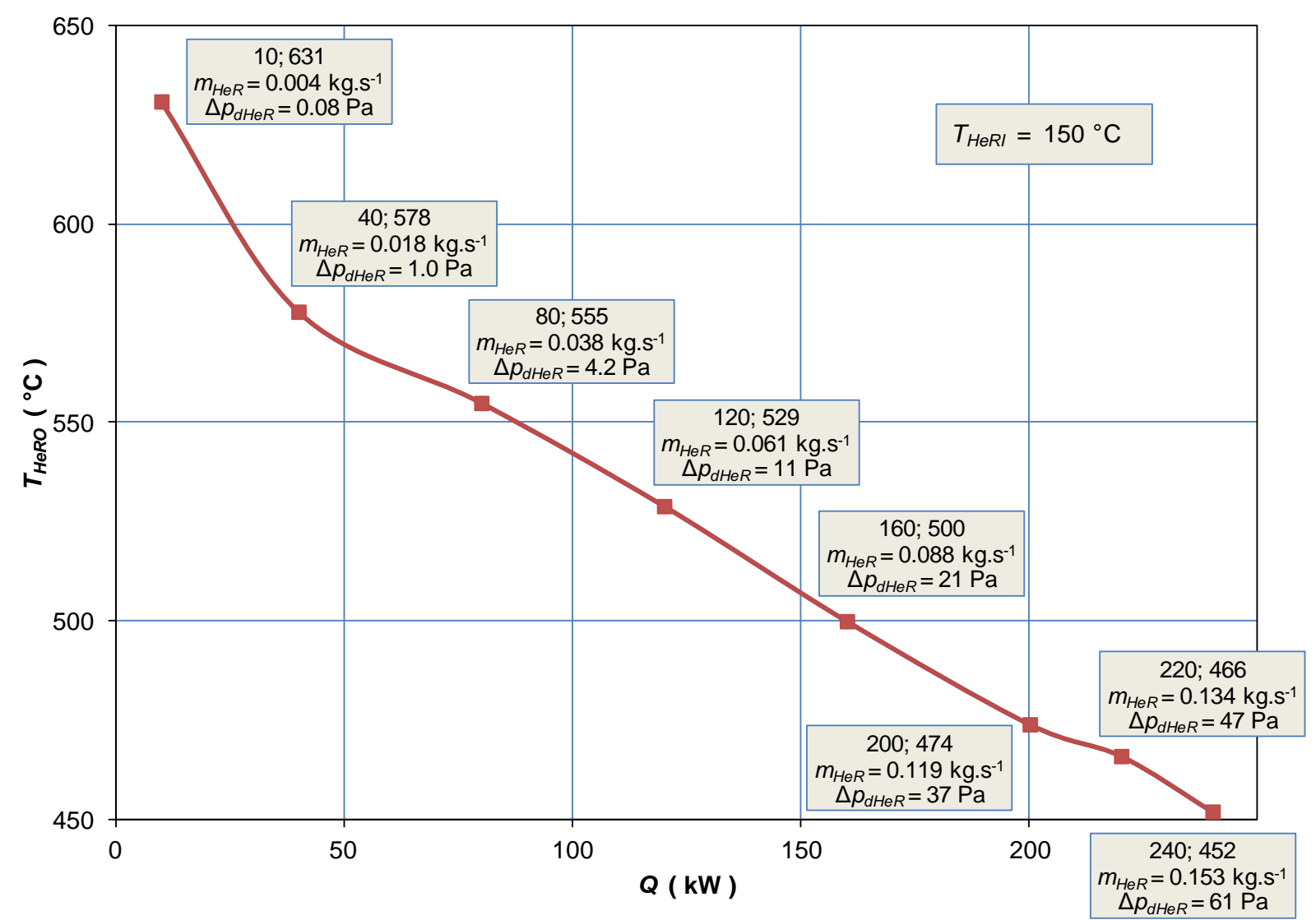

Fig. 5 The dependence of the helium temperature at the outlet of the GFR model on the transferred heat flow rate. 


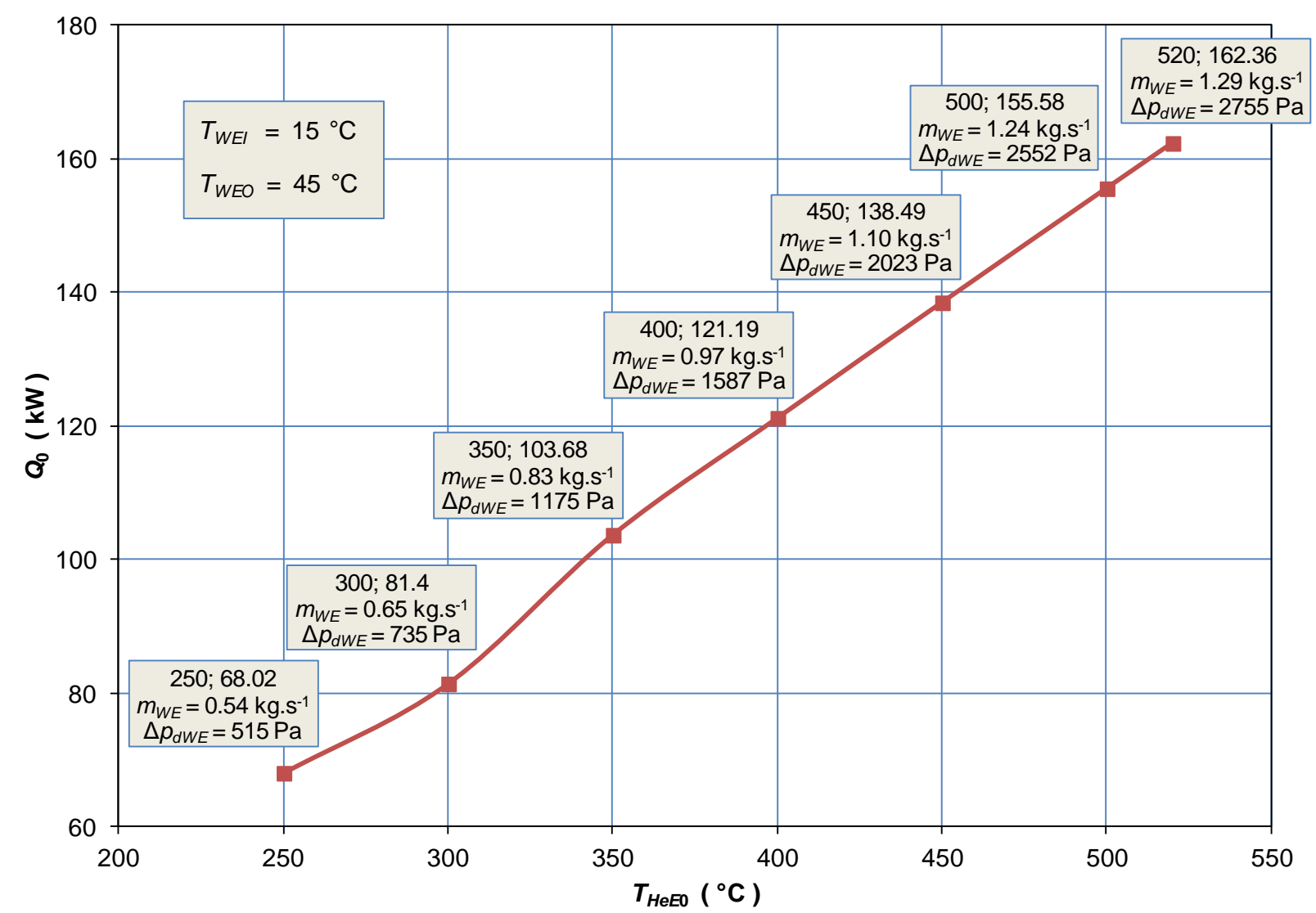

Fig. 6 The dependence of the initial value of the transferred heat flow rate in the DHR heat exchanger on the initial temperature of helium.

The Fig. 6 shows the dependence of the initial value of the transferred heat flow rate $Q_{0}$ in the DHR heat exchanger on the initial helium temperature $T_{H e E O}$ in this heat exchanger under the given conditions. The graph also contains the values of the corresponding mass flow of the cooling water $m_{W E}$ and the values of the pressure drop in the tube side of the DHR heat exchanger for cooling water $\Delta p_{d W E}$. The initial values of the transferred heat flow rate $Q_{0}$ and helium temperature $T_{H e E O}$ in the DHR heat exchanger correspond to the possible initial states of the start-up phase of the thermo-hydrodynamic process within the experimental helium loop. This operating state is characterised by a free convection in terms of the heat transfer kinetics between the helium and the solid surface of the heat exchange wall in the heat exchanger. In the initial state of the start-up phase of the process, it is assumed that the helium temperature in the shell side of the DHR heat exchanger is constant.

\section{Conclusion}

The results of the calculations document the magnitudes of the transferred heat flow rates from the heating rods to helium in the gas-cooled fast reactor (GFR) model and between helium and cooling water in the DHR heat exchanger model under the defined operating conditions. From the results, the actually achieved heat flows within the two main thermal- 
process units of the cooling system can be approximately identified also in association with its hydrodynamic properties which are presented in the paper [7]. This can be an input for further thermal and hydrodynamic optimisation of such helium cooling loop system.

It is important to emphasise that the validity of the presented results of the thermal process calculations of the DHR heat exchanger model and of the GFR model, as well as the hydrodynamic process calculations of the whole system of the experimental helium loop presented in the paper [7], is conditioned by the fulfilment of the baseline assumptions given in Tab. 1 which in the real system of the experimental helium loop, due to its inappropriate geometric configuration and non-optimised design, need not be permanently achieved. The heat exchanger calculations assume a steady state of its operation and therefore it is not possible to assess the non-stationary start-up phase of the heat exchanger operation in the defined helium loop system. In order to assess the final operating state of the DHR heat exchanger model, the whole system of the helium cooling loop, taking into account the specific geometric configuration of its workspaces, would have to be complexly solved. The calculations also do not take into account the effect of the secondary thermo-hydrodynamic phenomena (local circulation of helium due to local gradients of the temperature) that may arise in the helium working space of the DHR heat exchanger model or in the helium inlet and outlet areas of the heat exchanger at some operating states of the helium cooling loop. The position (the altitude relative to the position of the GFR model) and the orientation (e.g. horizontal, vertical, with a certain angle of inclination) of the DHR heat exchanger model relative to the gravitational acceleration direction within the helium cooling loop, as well as the location and mutual position of helium inlet and outlet within the heat exchanger, significantly affect the operation of the entire cooling system.

\section{ACKNOWLEDGEMENTS}

This contribution was created on the basis of the project "Research centre ALLEGRO" (ITMS project code: 26220220198) supported by Operational Programme Research and Development funded by the European Regional Development Fund.

\section{REFERENCES}

[1] M. Miletić, R. Fukač, I. Pioro, A. Dragunov. Development of gas cooled reactors and experimental setup of high temperature helium loop for in-pile operation. Nuclear Engineering and Design, 2014 (276), 87 - 97

[2] J. Berka, T. Hlinčík, I. Víden, T. Hudský, J. Vít. The design and utilization of a hightemperature helium loop and other facilities for the study of advanced gas-cooled reactors in the Czech Republic. Progress in Nuclear Energy, 2015 (85), 156 - 163

[3] I. A. Said, M. M. Taha, S. Usman, M. H. Al-Dahhan. Effect of helium pressure on natural convection heat transfer in a prismatic dual-channel circulation loop. International Journal of Thermal Sciences, 2018 (124), 162 - 173

[4] B. Knížat, P. Hlbočan, M. Mlkvik. CFD simulation of a natural circulation helium loop. In Scientific Proceedings Faculty of Mechanical Engineering STU in Bratislava, Nakladatel'stvo STU, Bratislava, 2015, 57 - 62

[5] F. Urban, et al. Modelovanie prirodzenej cirkulácie hélia v experimentálnej héliovej slučke. Výskumná správa projektu Výskumné centrum ALLEGRO, Strojnícka fakulta STU v Bratislave, Bratislava, 2016 
[6] V. Kutiš, J. Jakubec, J. Paulech, G. Gálik, T. Sedlár. CFD Analysis of Downcomer of Nuclear Reactor VVER 440. Journal of Mechanical Engineering - Strojnicky časopis, 2016 (66), No. 2, 55 - 62

[7] F. Dzianik, Š. Gužela. Hydrodynamic properties of high temperature natural circulating helium cooling loop. Journal of Mechanical Engineering - Strojnicky časopis, 2017 (67), No. 1, 29 - 36

[8] Š. Gužela, F. Dzianik, M. Juriga, J. Kabát. Shell and tube heat exchanger - the heat transfer area design process. Journal of Mechanical Engineering - Strojnícky časopis, 2017 (67), No. 2, 13 - 24

[9] VDI-Wärmeatlas. 10th edition. VDI-Gesellschaft Verfahrenstechnik und Chemieingenieurwesen (Ed.), Springer-Verlag, Berlin - Heidelberg - New York, 2006 